\title{
ANALYSIS OF SUBJECT DISCRETE MATHEMATICS PARTS AND PROPOSAL OF E-COURSE MODEL FOLLOWING PETRINETS FOR INFORMATICS \\ EDUCATION
}

Milan Turčáni, Petr Kuna

\section{Abstract}

Nowadays, quality Mathematical basis - Informatics is an inherent part of study. Mathematical basis is provided by Discrete Mathematics that is taught as a compulsory subject in stated study program in the Department of Mathematics. Authors clarify significance and importance of simple thematic units of subject Discrete Mathematics in teaching technical - system subjects in study programme Applied Informatics. Mentioned subject is being taught in first year of University study and knowledge that students acquire during the study of this course are the "cornerstone" for their further development in technical - system study. Justness and importance of individual topics were analysed based on the evaluation of questionnaires, in which pedagogues teaching profession al IT subjects alloted weighted coefficients to individual thematic units. Weighted coefficients were alloted based on the significance of the given topic of the subject Discrete Math, with regard to the IT subject they are teaching. Upon designing the e-course, experience with the creation of linear and branch teaching software were used. For the simulation of the transition of students through individual lessons as well as the whole course, authors employed the method of the teaching process simulation using Petri nets.
Univerzita Konštantína Filozofa, Nitra

pkuna@ukf.sk

ARTICLE INFO

Article type

Full research paper

doi: 10.7160/eriesj.2013.060101

Article history

Received: November 13, 2012

Received in revised form: March 19, 2013

Accepted: January 20, 2013

Available on-line: March 31, 2013

\section{Key Words}

Learning models, E-learning, Discrete mathematics, Petri nets, Technology Web 2.0 


\section{Introduction}

Significance of Mathematical support of Informatics education is often depreciated by students and most of them take it lightly what influenced their next studies. When they realize this fact it is often too late. One of the factors that affect the knowledge is diversity of students which are coming to study Informatics. Another factor is the learning standards that are valid at secondary schools. These standards are obligatory, but each school has some operational area and therefore this should be adjusted. The result is that some thematic units are not known from students coming to University. These discrepancies were partly eliminated when Discrete Mathematics was integrated into compulsory subjects.

Discrete Mathematics deals especially with discrete (discontinuous) structures researching. According to highpowered use of computers by solving the difficulties and different types of tasks, Discrete Mathematics overreaches the ambit of discrete analysis and comprises also a number of constructive methods developed for first-hand use of computers. Discrete Mathematics is relatively separate part of Mathematics. The main attribute is confidentiality, i.e. opposite of coherence and in broader sense it covers also disciplines like Numbers theory, Algebra, Symbol logic, Combinatory, Chart theory, Set theory and many others, which started their biggest development in the middle of $20^{\text {th }}$ Century which was well known for computer development (Toman, 2008).

In the article, authors describe not only the analysis of current status Discrete Mathematics education, but also the justness of single thematic units of Discrete Mathematics for single subjects of study programme Applied Informatics/Bc. Authors proposed e-course structure and content of Discrete Mathematics from obtained results with Web 2 technology support.
To ensure effective students graduation through educational course was used simulation of student passing through e-course method by Petri nets.

\section{Material and Methods}

\section{Analysis of the current state of teaching discrete math}

Discrete Math is a rather new field of mathematics dealing with discrete mathematic structures, which can be characterized by whole (integral) numbers, and are thus "countable". It is an opposite of mathematics, which deals with continuous structures characterized by real numbers, such as mathematic analysis. Development of discrete math was conditioned mainly by the development of informatics. In fact, discrete math is often understood as a part of informatics. Some mathematicians integrate only new mathematic disciplines, which originated in connection with the development of computer technology, into discrete math (Jablonski, 1982).

Discrete math is a standard component of education in informatics. The subject Discrete Math is an obligatory subject not only in study programmes of informatics fields of study in the Slovak and Czech Republic, but also in other countries, where Informatics is taught. This information was obtained through an analysis of web-sites of individual universities in Slovakia and abroad. An important form, which offered relevant information on the study of informatics, were information sheets of study programmes based on the contents of which it was necessary to compare individual thematic units of the subject and to find out to what extent they are consistent with the information sheet, according to which Discrete Math is taught at the Constantine the Philosopher University in Nitra, Slovakia. 
Based on the obtained contents of information sheets of the subjects Discrete Math 1 and 2 it is possible to define the aim and content of subjects Discrete Math 1 (DM1) and Discrete Math 2 (DM2):

\section{DM1}

This discipline focuses on the complementation and enlarging of the concepts forming the mathematical basis of informatics. Its task is to retrace and deepen basic concepts from the sphere of arithmetic, theory of sets, sententional calculus and boolean calculus, which find wide application in all spheres of informatics (Tomanová and Vozár, 2006).

\section{DM2}

This discipline focuses on the complementation and enlarging of the concepts forming mathematic basis of informatics. Its task is to retrace and deepen basic concepts from the sphere of combinatorics and theory of graphs with the focus on graph algorithms. It is a continuation of the subject Discrete math 1 (Tomanová and Vozár, 2006).

Having finished the analysis carried out at all universities within the Slovak and Czech Republic, which offered the study field Applied Informatics, we focused our attention to four Slovak and three Czech $\mathrm{u}$

niversities. The reason for this was to select adequate universities with a comparable focus and the study field/study programme mentioned above (Turčáni, Kuna, 2012).

Within the Slovak Republic the following universities were included:

- Constantine the Philosopher University in Nitra

- Comenius University in Bratislava
- Technical University in Košice

- Slovak Technical University in Bratislava

Within the Czech Republic the following universities were included:

- Ostrava university in Ostrava

- Charles University in Prague

- Masaryk University in Brno

Having compared individual thematic units of the subject Discrete Math within the selected universities in the Slovak and Czech Republic we found out that information sheets of the subjects Discrete Math 1, 2 are comparable and identical as to the contents. We can thus state that the teaching of the subject Discrete Math at the Faculty of Natural Sciences, Constantine the Philosopher University in Nitra is comparable with the ones at other universities.

\section{Justness of individual topics of the subject discrete math for individual subjects of the study programme Applied informatics/Bc.}

Identifying the justness of single thematic units which are taught on Informatics Department within mathematical base for individual subjects of study program Applied Informatics for bachelor degree was necessary to divide in two steps.

The first step by solving this issue was to find out the just ification of each thematic unit, which is being taught in Discrete Mathematics. Thematic units are specified in informational sheet of Discrete Mathematics. We compared the se units with thematic units of other Universities with similar focus. This analysis shows us that thematic units which are included into study are more or less the same as those taught at other. 
We requested teachers of individual subjects from Informatics Department which was the second step for discovering the justness of single thematic units. Number of subjects which teachers evaluated by balance ratio was 19. Number of teachers involved in this research was 11 . Number of thematic units for Discrete Mathematic subject 1 was 12 and for Discrete Mathematics 2 it was 11. The questionnaire was repeated two times according to Delphi method. Standard process of Delphi method is to request a group of teachers by questionnaires in the first round. Obtained data are being analyzed and statistical characteristics are being set (mainly median and quartile allowance). This conclusion is becoming a part of next questionnaire in the second round (Bílek, 2008).

The topics were taken over from information sheets for the subjects Discrete Math 1 and 2 for the study field Applied Informatics. The main task of the questionnaires was to find out the degree of importance and the meaning of thematic units of subjects Discrete Math 1 and Discrete Math 2 in the teaching of informatics study programmes.

The process of filling in the questionnaires took place at the Department of Informatics in the following stages:

- Selection of pedagogues (12 pedagogues participated in the interview)

- Comparison of answers; the most frequent proposals were marked in the second

- questionnaire,

- In the second round median was marked in the scale dispersion in the questionnaire,

- Pedagogues were submitted the adjusted questionnaire repeatedly and were asked to allot the weighted coefficient to individual thematic units,
- For the evaluation of the results of evaluation by pedagogues the Delphi method known also as the Delphi oracle was used. The Delphi method is a scheme of procedure of expert 's answering aimed at activating the stimulation of expert 's knowledge. The peculiarity, differentiating the method from expert's interview, consists in the fact that the process of answering is recurrent. In individual interlocked cycles pedagogues are individually acquainted with the results of previous cycles by an independent person, and based on that they can modify their evaluation (Bílek, 2008),

- Arithmetic mean with the application of all answers was used for the evaluation. The resulting value was calculated by dividing the sum of all answers by $\mathrm{N}$ pedagogues.

Weighted coefficients (the sum of the first and second cycle in the questionnaire), which were allotted by pedagogues to individual thematic units from the subject DM1 regarding their subject being taught, are presented in Table 1 . The values in line one - T1 through T12 in the table represent individual thematic units, which are taught within the subject Discrete Math 1. In the first column are presented abbreviations of subjects. 


\begin{tabular}{|l|c|c|c|c|c|c|c|c|c|c|c|c|}
\cline { 2 - 13 } \multicolumn{1}{c|}{} & T1 & T2 & T3 & T4 & T5 & T6 & T7 & T8 & T9 & T10 & T11 & T12 \\
\hline AP1 & 10 & 9,5 & 7 & 6 & 10 & 10 & 10 & 5 & 4 & 3 & 6 & 8 \\
\hline AP2 & 10 & 9,5 & 7 & 6 & 10 & 10 & 10 & 5 & 4 & 3 & 6 & 8 \\
\hline OS1 & 4,5 & 6 & 8 & 8 & 9 & 8 & 9 & 6 & 5,5 & 2 & 7 & 6 \\
\hline OS2 & 4,5 & 6 & 8 & 8 & 9 & 8 & 9 & 6 & 5,5 & 2 & 7 & 6 \\
\hline PS1 & 3 & 3 & 5 & 6 & 5 & 5 & 4 & 2 & 2 & 2 & 4 & 5 \\
\hline PS2 & 3 & 3 & 3 & 4 & 7 & 6 & 2 & 6 & 6 & 2 & 7 & 7 \\
\hline KOD & 10 & 8 & 6 & 6 & 8 & 4 & 8 & 10 & 8 & 4 & 8 & 4 \\
\hline PRO1 & 8 & 4 & 7 & 7 & 5 & 4 & 3 & 9 & 6 & 5 & 7 & 3 \\
\hline PRO2 & 7 & 4 & 6 & 6 & 5 & 4 & 2 & 6 & 5 & 4 & 6 & 4 \\
\hline PDA & 6,5 & 3 & 8 & 5,5 & 5,5 & 5,5 & 2,5 & 2,5 & 3 & 2,5 & 4,5 & 4 \\
\hline DS & 5,5 & 4 & 9 & 6 & 6,5 & 5 & 2,5 & 3 & 4 & 2 & 3,5 & 4,5 \\
\hline FJA & 7 & 3 & 9,5 & 9 & 4 & 4 & 4 & 8,5 & 9 & 2 & 9 & 5 \\
\hline PG & 7,5 & 6 & 7 & 6 & 5,5 & 5,5 & 6 & 7,5 & 7 & 3,5 & 9 & 5,5 \\
\hline PDM & 2,5 & 2,5 & 6 & 4 & 3 & 3 & 2 & 2 & 2 & 2 & 4 & 4 \\
\hline UDM & 2,5 & 2 & 6 & 4 & 3 & 3 & 2 & 4 & 2 & 2 & 3 & 3 \\
\hline TAZ & 9 & 9,5 & 6 & 6 & 4 & 3 & 2 & 9 & 4 & 2 & 4 & 4 \\
\hline UI & 10 & 5,5 & 9 & 7 & 9,5 & 6 & 4 & 4 & 3,5 & 3,5 & 4 & 4,5 \\
\hline IS & 4,5 & 3 & 6 & 5 & 5 & 4,5 & 2,5 & 2,5 & 3 & 3 & 3,5 & 4,5 \\
\hline NMO & 2,5 & 2 & 7 & 4 & 3 & 3 & 2 & 4 & 2 & 2 & 3 & 3 \\
\hline Total & $\mathbf{1 1 7 , 5}$ & $\mathbf{9 3 , 5}$ & $\mathbf{1 3 0 , 5}$ & $\mathbf{1 1 3 , 5}$ & $\mathbf{1 1 7}$ & $\mathbf{1 0 1 , 5}$ & $\mathbf{8 6 , 5}$ & $\mathbf{1 0 2}$ & $\mathbf{8 5 , 5}$ & $\mathbf{5 1 , 5}$ & $\mathbf{1 0 5 , 5}$ & $\mathbf{9 3}$ \\
\hline
\end{tabular}

algorithm), T1 (Basis of prepositional calculus), T5 (Diophant's equations). This means that the given thematic unitsreached the highest weighted coefficient.

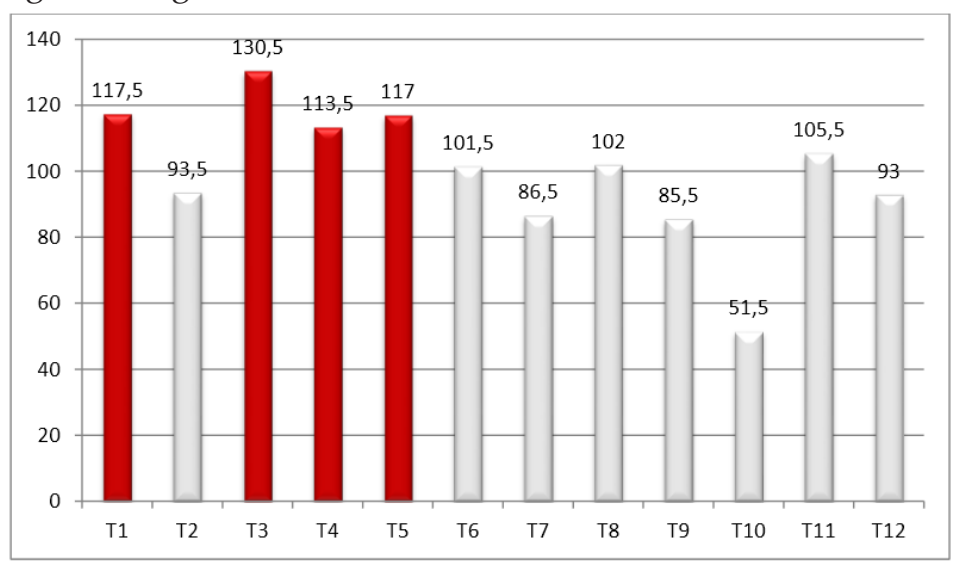

Figure 1: Graphic depiction of the evaluation of DM1

Weighted coefficients (the sum of the first and second cycle of the questionnaire), which were allotted to in dividual thematic units from the subject DM2 by pedagogues, regarding their subject taught, are presented in Table 2 . The values in line one $\mathrm{T} 1$ through $\mathrm{T} 11$ in the table represent individual thematic units, which are taught within the subject Discrete Math 2. In the first column are presented abbreviations of subjects.

Table 1: Weighted coefficient of thematic units in the subject DM1

It is obvious from the graphic illustration Figure 1 that pedagogues marked as the most important the thematic units topics T3 (Relation of divisibility and its attributes), T4 (The least common divider, the least common multiple, Euclid 's 
the graph peak grade theorem, the theorem on the existence of the graph with the given grades of peaks, an algorithm for the finding out whether the given sequentiality is graphic), T4 (Continuity of the graph - sequence, route, trace, connection, course, the theorem on the number of sequences of the length between two peaks of the graph), T5 (Algorithm for the testing of graph continuity). This means that the given thematic units reached the highest weighted coefficient.

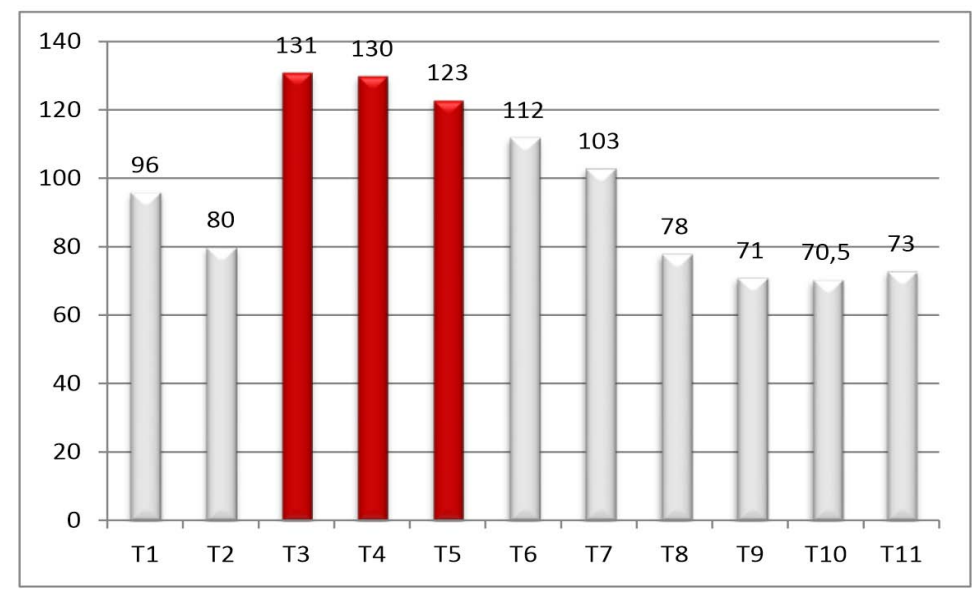

Figure 2: Graphic depiction of the evaluation of DM2

\section{Results}

To receive the final order, we need to create weight ratio total from first and second cycle. Final values of both cycles represents

Table 2: Weighted coefficients of thematic units in the subject DM2 for the subject DM1 Figure 3 and for the subject DM2 Figure 4.

Values, which are presented in Table 2, are represented by Figure 2. The following topics were marked by pedagogues as the most important thematic units: T3 (Definition of the graph, 


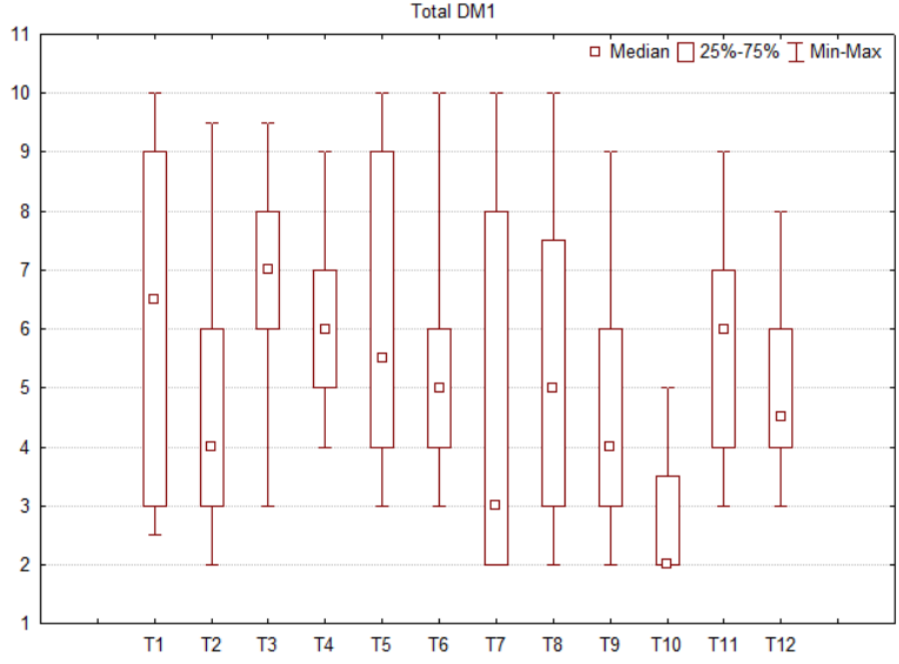

Figure 3: Box plot - final evaluation of thematic units for DM1

As its obvious from Figure 3, thematic units T1, T3, T4 and T11 reached the highest weight ratio. Pay your attention on median value, which is for these thematic units one degree higher than median values for other thematic units. For thematic units T1, T5, T7 and T8 was the weight ratio diversity the highest. As by first so by second cycle of subject Discrete Mathemathics 1, thematic unit T10 reach the lowest weight ratio. Median value for this thematic unit is 2. For thematic units T3, T4, T6 and T10 teacher answers were most intergrated.

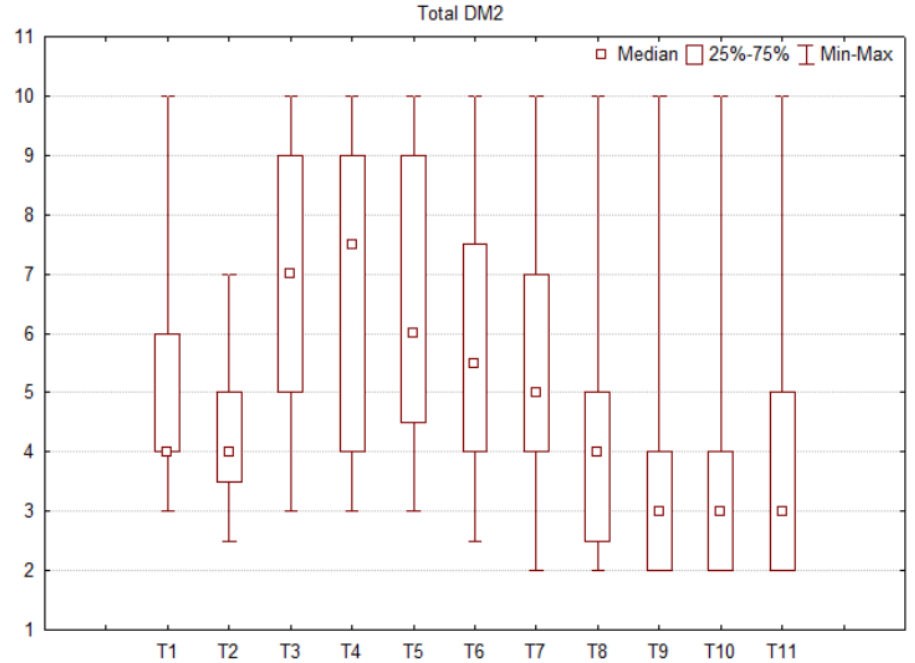

Figure 4: Box plot - final evaluation of thematic units for DM2

As its obvious from Figure 4, thematic units T3 and T4 reached the highest weight ratio. Pay your attention on median value, which is for these thematic units one degree higher than median values for other thematic units. This group should include thematic unit $\mathrm{T} 5$ because of third highest median value. However, thematic unit T4 has the highest diversity of weight ratios. 


\section{Proposal of the structure and content of the e-course of the subject discrete math with the support of Web 2.0 technology}

To sustain a good educational trend by using modern ICT forces us to look for to implement the newest methods and forms of teaching. At present, those seem to be AHS that present a higher form of e-learning. (Turčáni and Kapusta, 2008)

The proposal of the structure of the course draws from the knowledge, which was obtained from the questionnaires, in which pedagogues allotted weighted coefficients to individual thematic units. In the subject DM1 the most important thematic units were as follows: T3 (Relation of divisibility and its attributes), T4 (The least common divider, the least common multiple, Euclid 's algorithm), T1 (Basis of prepositional calculus), T5 (Diophant's equations).

In the subject DM2 the highest weighted coefficient was reached by the following units: T3 (Definition of the graph, the graph peak grade theorem, the theorem on the existence of the graph with the given grades of peaks, an algorithm for the finding out whether the given sequentiality is graphic), T4 (Continuity of the graph -sequence, route, trace, connection, course, the theorem on the number of sequences of the length between two peaks of the graph), T5 (Algorithm for the testing of graph continuity). Thematic units with the highest weighted coefficient show direct influence on further studies of students.

The input capital of inventions, themes and creativity, selection of the way and time of realization, lies within the pedagogue 's authority himself/herself. This would require a creative, well prepared teacher with competences, skills and knowledge not only from the sphere of technical education, but also many other areas, last but not the least, educated or literate in the sphere of ICT (Burianová and Magdin, 2009).

The solution of courses itself will be realized in two ways, either by a branch or linear teaching software. Branch software is particularly favourable when the provision and manipulation with new concepts is in question. Its fundamental asset is that it allows the student learning the content of education for choosing his individual way along the line, which corresponds to his intellect and previous knowledge. The linear teaching software is characterized by the fact that the learning contents is presented in small sections, however, the best way is to present just a single section in each step. The units with the highest weighted coefficient follow the subjects of the technical - system nature. Among these subjects are Computer Architecture (AP), Operation Systems (OS), Computer Networks (PS). These subjects form a part of the study programme Applied Informati $\mathrm{cs} / \mathrm{Bc}$.

From the perspective of computer terminology, tactics are the individual steps (sub-processes of learning a student) that are observable, registrable and measurable. With the terminology used and its content, we will work in drawing up rules for assigning the appropriate parts of the study support to the different types of students.

Various teaching methods consist of meaningful sequence of learning steps. Learning process phasing into three basic parts can be found in many publications:

- Motivating - is intended to arouse the student interest in teaching content,

- Exposing - phase of the passing on the curric 
- ulum content,

- Fixing - allows consolidating of students' gained knowledge, skills and habits (Kostolányová, Czeczotková and Šarmanová, 2010).

\section{Linear teaching software}

By means of these Petri nets we modelled the structure of future e-course for the subjects Discrete Math 1 and Discrete Math 2. Petri nets seem to be the most effective way of their simulation and realization.

The beginnings of model ling the user stretch to teaching systems. The aim of model ling the user is thus preserving the values connected with the user, which reflect the level of his knowledge and their employment upon adjusting the system (Turčáni, 2010). They prescribe for all students a fixed and definite sequence of steps along one line.The teaching contents is taught in small sections of information, however, the best way is to present just a single section in each step. At need, the created concept is practised until the student manages it. Adding one concept to the other the student gets acquainted with the whole subject - matter and its whole problem. Conciseness of steps does not allow for the expansion of the prosaic style of explanation, so linear software is monotonous and after a certain time it becomes less interesting and very tiring. From the beginning until the end stretches one straight line compound of rules, exercises and answers Figure 5. Opponents of a linear software state that very small steps interrupt the student 's trains of thought in an undesirable way. According to practical experience is linear programming suitable for the teaching of basis and principles of the problem, moreover, for the forming of the word -stock and new concepts (Klimeš, Balogh, 2010).

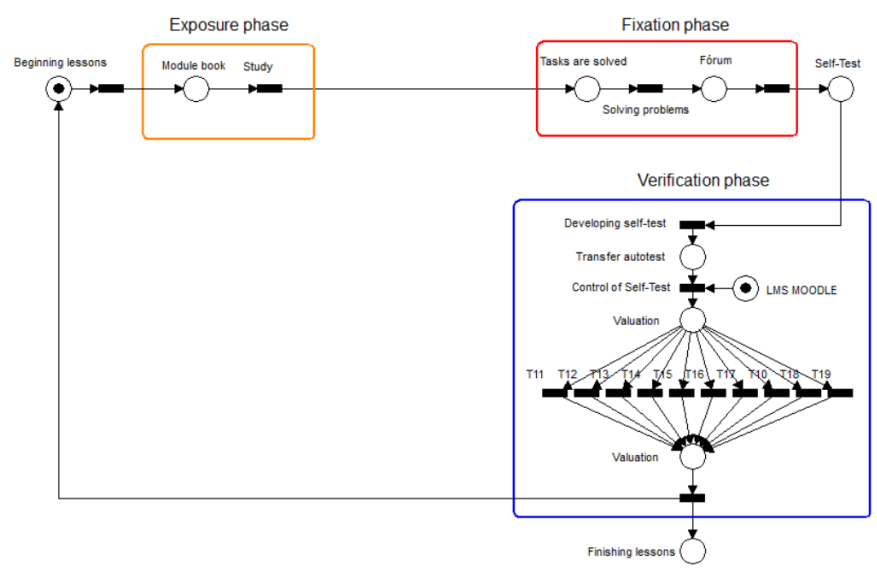

Figure 5: Linear model of the student's transition in the lesson

\section{Branch teaching software}

When solving the problems, they allow for various procedures. Alternatives of "branches" of the programme finally lead to the successful joint coping with the problem. Every student, however, passes the way defined in advance, while the length corresponds to his personality, knowledge and capability. When teaching facts the programme has a clear main line, from which side lines shaped in different ways evert and then connect again Figure 6. 


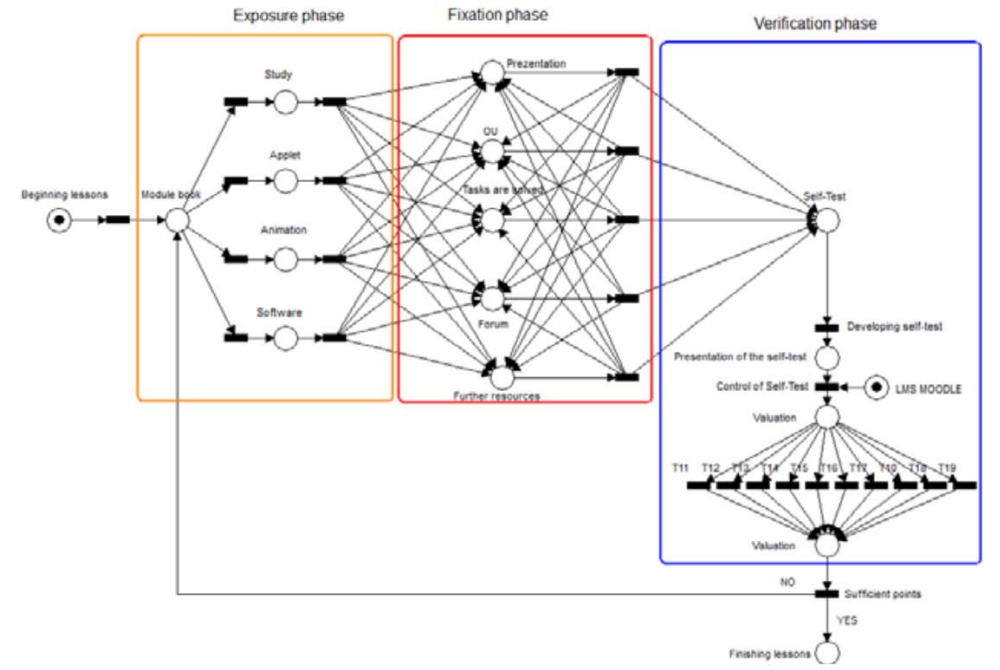

Figure 6: Branch model of the student's transition through the lesson

The main line usually permits the procedure in larger and more demanding steps, which can be coped with only by a gifted student, correctly answering the inserted check questions; shorter and easier steps for less endowed students, or those working more slowly, are typical for side branches. Exercises for a successful practising of the given subject - matter, tasks, instructions and directives are inserted in them, facilitating the student's solution of the problem, or using a visual aid or sequence, complementing the content of education in order to strengthen the opinion or fact. Larger information content of individual steps at the branch software admits its activation and for the student it is more interesting when presented in the form of a dialogue. Branch software is especially suitable in case when the provision and manipulation with new concepts are concerned. Its basic contribution is that it allows the student for choosing an individual way in acquiring the content of education along the line, which corresponds to his intellect and previous knowledge. Each of these basic types of software has two further variant s according to the fact that whether the student forms the check questions, or chooses them out of the offered variants of answers (Klimeš, Balogh, 2010).

\section{Modelling the student's transition through the course using Petri nets}

The student's transition within the whole course is simulated using a linear Petri net Figure 7. According to the current position of the token in the model Petri net we can find out in which section of the course the student is momentary situated, or to which lesson or setting he is addicted himself. The situation in reality need not be so simple. Settings, which should be elaborated by the student, will be submitted for inspection and subsequent evaluation to the pedagogue, who will assign the assessment. If the student does not reach the required number of points, he is allowed to make a correction to the setting. We expect that during the semester the student studied materials and continuously elaborated settings in all ten lessons over all the defined points in the Petri nets. We suppose that this procedure of the student was linear. The locations (L1, L2, L3, L4, L5, L6, L7, L8, L9, L10) represent individual lessons, through which the student passes, and points (P1, P2, P3, P4, P5, P6, P7, $\mathrm{P} 8, \mathrm{P} 9, \mathrm{P} 10)$ are the check settings (self - tests) for the verification whether the student understood the given lesson. 


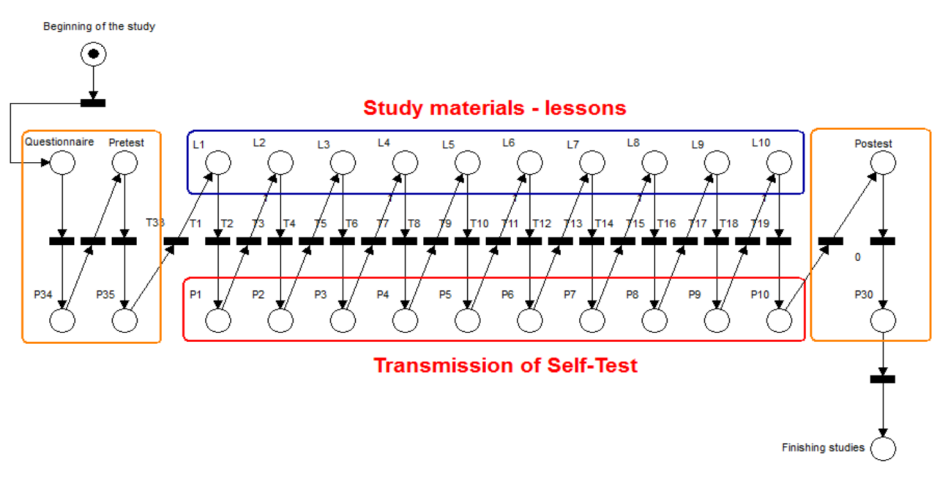

Figure 7: Transition of the student within the course using the linear Petri net

The hand - over of settings takes place as follows:

- Study of materials

- Solution of setting

- Hand -over of setting

- Assessment by pedagogue

- Allotment of the number of points, or correction of setting and the following adjustment of the number of points.

If the student does not reach the required number of points, she/ he will have to repeat the given lesson. If she/he reads the lesson through, she/he will be allowed to pass the check setting again. The final function of the learning management system (LMS) is routing the communication depending on the student's knowledge and abilities and according to that changing the quantity and ambitiousness of the material offered to the student. Interaction between student and LMS in the process of teaching and learning is a composite process. The aim of the system for the teaching control is to regulate the communication according to the student's knowledge and ability and thus modify the amount and sophistication of submitted materials for the student. (Balogh, Koprda, 2012)

\section{Discusion}

To process thematic units we used linear and branched educational programmes. Linear educational programm was used by thematic units with lower weight ratio. This means that for the subject Discrete Mathematics 1 we are talking about thematic units T2, T5, T6, T7, T8, T9, T10 and T12. For the subject Discrete Mathematics 2 we are talking about thematic units T1, T2, T6, T7, T8, T9, T10 and T11. Branched educational programme was used for thematic units with the highest weight ratio. We found out that the most important thematic units from the subject DM1 are T1 (Basic of propositional count), T3 (Relation of divisibility and its attributes), T4 (least common divider, least common multiple, Euclides algorithm), T11 (Hamilton figures). From the subject DM2 we are talking about thematic units T3 (Figure definition, theorem about figure top degrees, theorem about figure existence with given top degrees, algorithm to find out if given sequence is figureable), T4 (Figure continuity sequence, pull, route, connection, line, theorem about sequence length number $\mathrm{k}$ between two tops of figure), T5 (Algorithm to test figure relationships). Thematic units with the highest weight ratio have straight impact on further study. Thematic units with the highest weight ratio are followed by technical system subjects. Within these are Computer Architecture (CA), Operational systems (OS), Computer nets (CN). All of them are compulsory subjects of study programme Applied Informatics/ Bc. 


\section{Conclusion}

Authors in their contribution attempted at describing the proposed structure of e-learning course in the subjects Discrete Math 1 and 2 in details. They expected that in this manner adjusted materials will have a direct impact on the knowledge of students. The knowledge could become long-lasting, which will cause an increase in their expertness upon their further studies.

For the detection accuracy and efficiency of our proposed methodology was used to experiment, in which students would be divided into two groups: control and experimental. The control group undergoing conventional teaching method and the experimental group would enjoy learning with our suggested model wi th the implemented e-course in the Moodle LMS. Research sample was composed by first year students what represent age group 19-38 years. The whole research sample composed 107 students with 91 men (85,05\%) and 16 women (14,95\%). From this 107 students the control group was composed by 72 students with 59 men $(81,94 \%)$ and 13 women $(18,06 \%)$. Then the experimental research sample was composed by 35 students with 32 men $(91,43 \%)$ and 3 women $(8,57 \%)$. The evaluation of learning outputs is a complex process. The efficiency measurement of individual teaching methods is very difficult, because there are many factors, which influence such efficiency together; it is practically impossible to extract the impact of one specific factor and analyze it separately ( Houška, Houšková Beránková, 2011).

Both groups have taken control test from Discrete Mathematics before using e-courses. After finishing semester students completed final test. Both groups results were compared and statistically processed using mentioned methods. Expected result should reflect in higher knowledge of Discrete
Mathematics and also by obtaining knowledge from technical informatical subjects like: Computer Architecture, Operational systems, Computers nets, Computer Graphics and other areas of teaching Informatics field of study for students of KI FPV UKF in Nitra.

\section{References}

Balogh, Z. and Koprda, S. (2012) "Modeling of Control in Educational Process by LMS", 9th International Scientific Conference on Distance Learning in Applied Informatics, pp. 43-51, ISBN: 978-80-558-0092-9.

Bílek, M. (2008) Expertní posuzování delfskou metodou v oborově - didaktickém výzkumu Bratislava : PřF UK, 2008, pp. 16-18., ISBN 978-80-223-2582-0.

Burianová, M. andMagdin, M.(2009)Project learning - effective alternative educationstudents using ICT. In: Trends in education: Information Technologies and technical education, Olomouc, Votobia, pp. 402-407., ISBN 978-80-7220-316-1.

Houška, M., Houšková Beránková, M., (2011) “The Impact of Multimedia Lectures onStudents Performance in Two Specific Subjects", Journal on Efficiency and Responsibility in Education and Science, Vol. 4, No. 4, pp. 187-186, ISSN 1803-1617.

Jablonský, S. (1982) Úvod do diskrétnej matematiky, Alfa, Bratislava.

Klimeš, C. and Balogh, Z (2010) 'Managing educational process in LMS with using Petri nets', In: DIVAI 2010, Nitra : UKF, pp. 108-109., ISBN 978-80-8094-691-3.

Kostolanyová, K., Czeczotková, B. and Šarmanová, J. (2010) 'Analysis of Teaching Styles of Teachers in the Contex of 
E-learning. In: Information and Communication Technology in Education', Ostravská univerzita, pp. 111-115., ISBN 978-807368-775-5.

Tomanová, J. and Vozár, M. (2006) 'E-learningový kurz diskrétnej matematiky.'In : DIVAI 2010, Nitra : UKF, pp. 255258., ISBN 80-8050-975-1.

Turčáni, M. (2010) 'Dištančné vzdelávanie a e-learning v prípave študentov informatických odborov', In: Technológia vzdelávania, pp. 2-7., ISSN 1338-1202.

Turčáni, M. and Kapusta, J. (2008) 'System for Adaptive Annotation of Hyperlinks in the Conditions of University Courses from the Field of Informatics', Journal on Efficiency and Responsibility in Education and Science, Vol. 1, No. 2, pp. 38-43, ISSN 1803-1617.

Turčáni, M. and Kuna, P. (2012) "Modelling the Student's Transition Through the E-course" Discrete Math" Using Petri Nets", 9th International Scientific Conference on Distance Learning in Applied Informatics, pp. 319-328, ISBN: 978-80-558-

0092-9. 